\title{
Lignoceric Acid
}

National Cancer Institute

\section{Source}

National Cancer Institute. Lignoceric Acid. NCI Thesaurus. Code C68387.

A saturated fatty acid with a 24-carbon backbone. Lignoceric acid occurs naturally in wood tar, various cerebrosides, and in small amount in most natural fats. 